\title{
THE COST OF AUTOMOTIVE POLYMER COMPOSITES: A REVIEW AND ASSESSMENT OF DOE'S LIGHTWEIGHT MATERIALS COMPOSITES RESEARCH
}

\author{
Sujit Das \\ Energy Division \\ Oak Ridge National Laboratory \\ Prepared for the \\ Office of Advanced Automotive Technology \\ Office of Transportation Technologies \\ U. S. Department of Energy
}

January 2001

OAK RIDGE NATIONAL LABORATORY

Oak Ridge, Tennessee 37831

managed and operated by

UT-Battelle, LLC

for the

U.S. DEPARTMENT OF ENERGY

under contract No. DE-AC05-00OR22725 


\section{TABLE OF CONTENTS}

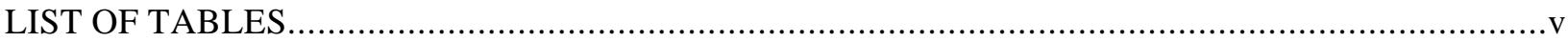

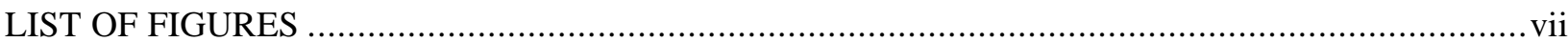

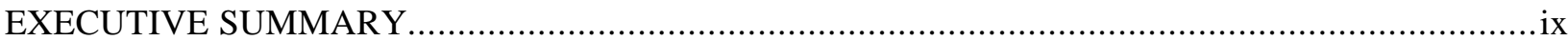

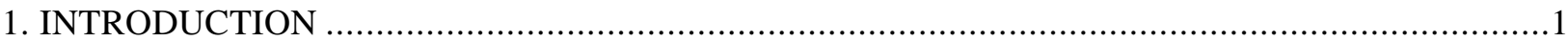

2. CURRENT STATUS OF COMPOSITES IN AUTOMOTIVE APPLICATIONS ............................

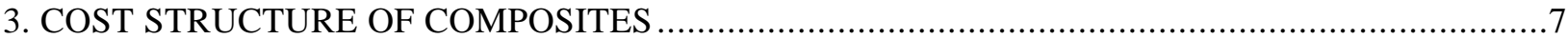

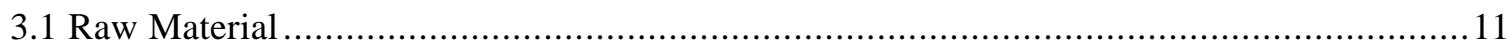

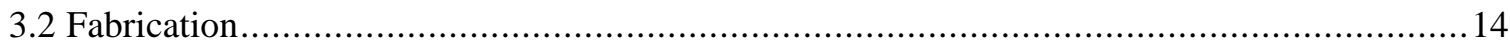

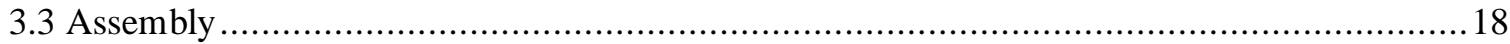

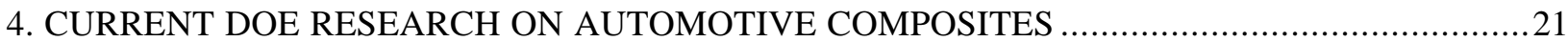

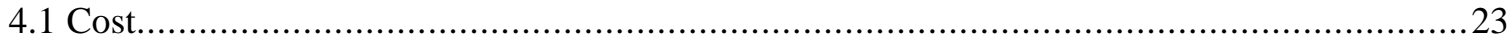

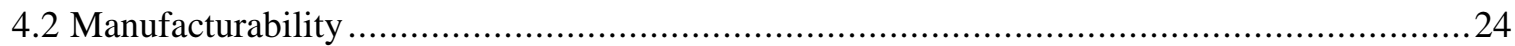

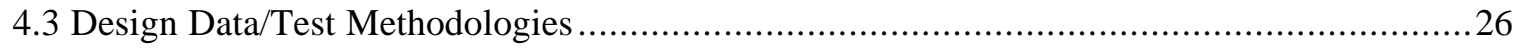

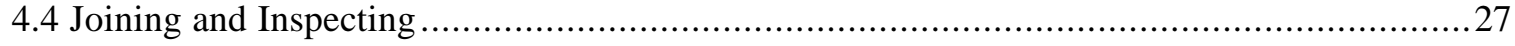

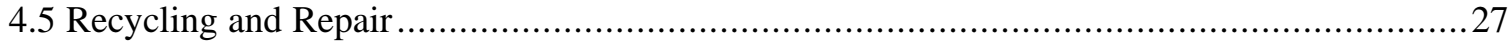

5. CONCLUSIONS

REFERENCES ............................................................................................................ 


\section{LIST OF TABLES}

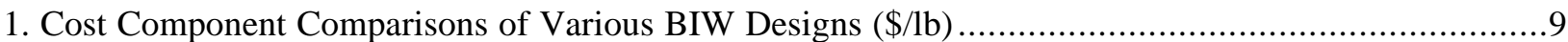

2. A Comparison of the Most Commonly Used Composite Molding Processes..................................15

3. A List Of Polymer Composite Projects Currently Funded By The DOE Lightweight Materials Program and Automotive Composites Consortium....................................................................22 


\section{LIST OF FIGURES}

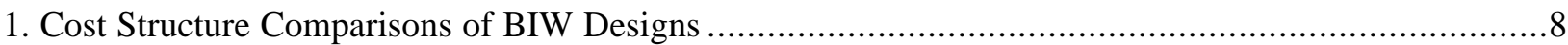

2. Carbon-reinforced Thermoplastics Moncoque Sensitivity to Carbon Fiber Cost..............................11

3. Breakdown of Carbon Fiber Production Cost ............................................................................ 14

4. Applicability of Various Composite Manufacturing Technologies, by Annual Production and Part

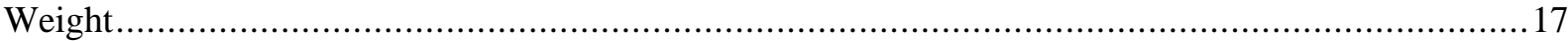

5. Cost Comparison of Different BIW Designs by Component...................................................19 


\section{EXECUTIVE SUMMARY}

Polymer composite materials have been a part of the automotive industry for several decades but economic and technical barriers have constrained their use. To date, these materials have been used for applications with low production volumes because of their shortened lead times and lower investment costs relative to conventional steel fabrication. Although glass fiberreinforced polymers dominate the composite materials used in automotive applications, other polymer composites, such as carbon fiber-reinforced polymer composites, show great promise. These alternatives are attractive because they offer weight reduction potential twice that of the conventional glass fiber-reinforced thermoset polymers used today.

The major thrust of this paper is an examination of the economic viability of polymer composites. The paper also examines how the R\&D supported by the U.S. Department of Energy Office of Advanced Automotive Technologies Lightweight Materials Program is responding to the needs of the industry, specifically from an economic viability perspective.

Based on a literature review of the cost studies of composites, some general qualitative trends in the economic viability of composites were observed. To date, most of the cost analyses of polymer composites are for body-in-white (BIW) applications because of the significant weight reduction potential these offer. The viability of composites is still predominantly seen in non-structural elements such as the bolt-on exterior panels of today's vehicles, and most composites are glass fiber-reinforced thermoset polymers such as SMC used in niche-market vehicles with annual production volumes of less than 80,000. At a higher annual production volume of 250,000, for example, an evaluation of the most efficient composite monocoque design indicates that the cost of glass fiber-reinforced thermosets and carbon fiber-reinforced thermoplastics are $62 \%$ and $76 \%$ higher than the conventional steel unibody. Even on a life cycle basis, the cost of polymer composites is estimated to be higher than steel unibodies. For composites to be cost competitive on a part-by-part substitution, improvements are necessary in cycle times and material utilization, which in some cases have been estimated to currently contribute $60 \%$ and $21 \%$, respectively, of the total cost of carbon-fiber-reinforced thermoplastics. The material cost plays a key role in the economic viability of polymer composites, particularly at higher production volumes and for carbon fiber-reinforced 
thermoplastics composites. The carbon fiber cost needs to drop by $50 \%$ (i.e., $\$ 3-\$ 5 / 1$ b range) and smaller cost reductions in other thermoplastic materials are needed for the composites to be economically viable.

The U.S. Department of Energy, in partnership with the USCAR's Automotive Composites Consortium is sponsoring research under the Lightweight Materials Program that seeks to overcome the barriers to more widespread use of composites in automotive applications. DOE is attempting to take a comprehensive look at the research needs of the composites industry and has prioritized certain areas such as low cost carbon fiber production, thermoplastic structural composites, and the development of new reinforcement technologies such as the nanocomposite technology. Its research portfolio is appropriately focused both in its ongoing research and its five-year research plan that covers five major areas of barrier, i.e., cost, manufacturability, design data and test methodologies, joining and inspection, and recycling and repair. Although cost reduction is a pervasive factor in all its composites $R \& D$ activities, it is appropriate to focus the "cost" area on materials, primarily carbon fiber. To improve the manufacturability of polymer composites, development of high-volume production manufacturing processes should remain one of DOE's research priorities. More research is needed in the areas of carbon fiberreinforced polymer composites for these to be economically viable automotive materials. It is clear that for polymer composites to become the material choice for automakers, an aggressive R\&D portfolio should be followed to achieve major breakthroughs that are necessary for several orders of cost reduction. 


\section{INTRODUCTION}

Polymer composite materials have been a part of the automotive industry for several decades, with early application in the 1953 Corvette. These materials have been used for applications with low production volumes, because of their shortened lead times and lower investment costs relative to conventional steel fabrication. Important drivers of the growth of polymer composites have been the reduced weight and parts consolidation opportunities the material offers, as well as design flexibility, corrosion resistance, material anisotropy, and mechanical properties. Although these benefits are well recognized by the industry, polymer composite use has been dampened by high material costs, slow production rates, and to a lesser extent, concerns about recyclability. Also impeding large scale automotive applications is a curious mixture of concerns about material issues such as crash energy absorption, recycling challenges, competitive and cost pressures, the industry's general lack of experience and comfort with the material, and industry concerns about its own capabilities (Flynn and Belzowski 1995).

Polymer composite materials are generally made of two or more material componentsfibers, either glass or carbon, reinforced in the matrix of thermoset or thermoplastic polymer materials. The glass-reinforced thermoset composites are the most commonly used composite in automotive applications today, but thermoplastic composites and carbon fiber-reinforced thermosets also hold potential. It has been estimated that significant use of glass-reinforced polymers as structural components could yield a $20-35 \%$ reduction in vehicle weight. More importantly, the use of carbon fiber-reinforced materials could yield a $40-65 \%$ reduction in weight.

Many R\&D efforts are currently underway both within and outside the composites industry, where, for example, the DOE Lightweight Materials Program is working in collaboration with the Automotive Composites Consortium (ACC) to remove existing technological barriers and enhance composites' viability in the automotive marketplace. This paper will address the current use of composites in automotive applications, the challenges for expanded use, and the research to respond to those challenges. The review of the research is limited to that conducted under the U.S. Department of Energy's Office of Advanced Automotive Technologies Lightweight 
Materials (LWM) Program. The major focus of this paper is to examine the current economic viability of these materials, and, in that context only, to assess on what specific areas ongoing $\mathrm{R} \& \mathrm{D}$ needs to be focused to improve the materials' viability for automotive applications. It is beyond the scope of this paper to examine in detail the ongoing, technical developments or accomplishments made to date outside DOE LWM. Since cost is the focus of this assessment, the published literature about the costs of composites is the basis for reviewing the focus of the DOE LWM R\&D program with regard to its ability to further enhance composites' economic viability and for determining further needs for cost modeling. 


\section{CURRENT STATUS OF COMPOSITES IN AUTOMOTIVE APPLICATIONS}

Today's average automobile is about $8 \%$ plastics and composites (i.e., about 245 lbs/vehicle), a small increase from 170 lbs during the mid-1970s (Demmler 1998). Small, fuelefficient passenger vehicles generally contain more composites relative to their total weight than do larger vehicles, but larger vehicles such as minivans contain more composites by weight. Composites provide a wide range of potential automotive applications-body panels, suspension, steering, brakes, and other accessories - where the demand varies widely by application. The application of composites is still predominantly in non-structural elements of the vehicle today, and is mostly glass fiber-reinforced thermoset polymers used in niche-market vehicles with annual production volumes of less than 80,000 . Sheet molding composites (SMC) predominate composites use for semi-structural applications because they are highly competitive for bolt-on exterior panels such as hoods, decklids and fenders, especially in lowand mid-volume cars and trucks such as Corvette, Dodge Viper, and AP minivans. SMC is one of the processes that offer the potential application of the molded in-color technology, saving cost and emissions of the unnecessary painting operation. About 242 million lbs of SMC were used by automakers in 1999, up 160\% in the last five years. By 2003 it will be 315 million lbs$30 \%$ more than in 1999-largely because of styling flexibility, technology developments, and weight and cost savings that make SMC an attractive alternative to steel or aluminum (Millerschin 1999). Of 1998's total body panel market, composites enjoyed a share of 6\%, aluminum 3\%, and steel $91 \%$ in terms of total material consumption (James 1999). Some existing, specific SMC applications include fenders of the GMT 800 Chevrolet Silverado and F350, and as cowl in Toyota Sienna. Ford is using a glass-fiber composite for a one-piece cargo area for its Explorer Sport Trac SUV/PU hybrid (Defosse 1999).

In addition to body panels, the current, limited automotive applications of composites include bumper systems, instrument panels, leaf springs, drive shafts, compressed natural gas fuel tanks, intake manifolds, wheel covers, valve covers, fascia supports, and cross vehicle beams. For example, the share of composite drivetrain components used in 2000 model year passenger cars was only $6 \%$ of total composites used (ACA 2000). There have been only a few body-in-white composite applications to date. For example, the most efficient monocoque 
design was used in the very-low-production volume Consulier sports car and a composite variation on the Ford Taurus as a developmental technology.

Fiber-reinforced thermoplastics have the typical advantages of polymer matrix composites such as high weight savings, high strength, high stiffness, corrosion resistance, parts integration, and energy absorption. In addition, they have an indefinite shelf life, are recyclable, and are feasible for automated, high volume processing with a potential for rapid and low-cost fabrication. However, thermoplastic use is very limited today because of a lack of dimensional stability and low heat distortion temperatures not suitable for e-coat ovens used in existing assembly plants. The most used thermoplastics are glass filled thermoplastics developed for a variety of applications from intake manifolds to engine covers, and to a lesser extent for body panels. The 1995 Nissan Sentra served as the first use of thermoplastic (DuPont's Minlon mineral-reinforced nylon) for valve covers in North America. Other applications include cylinder head covers (BMW's 2.0- to 2.8-L, 6 cylinder engines) and engine valve covers (using DuPont's Zytel glass-reinforced nylon 6,6 resin). Thermoplastics have gained popularity in select body panels as DuPont's Bexloy K 550 glass-reinforced PET polyester-based composite was selected for fenders on first-generation Chrysler LH cars (the 1993 Dodge Intrepid, Eagle Vision, Chrysler Concorde and New Yorker) (Buchhloz 1998). General Motors also uses fiberreinforced thermoplastics for vertical body panels in its Saturn vehicle model. DaimlerChrysler demonstrated the potential use of thermoplastics in automobiles with its Chrysler Composite Vehicle (CCV) program, where the thermoplastic approach to large injection-molded body technology (LIMBT) has been used. The program has considered thermoplastics because of their high potential for reducing vehicle weight, manufacturing complexity and concomitant assembly cost, while providing a body with the appearance, performance and capacity of today's full-size, mass-produced vehicles (Chapman 1999).

Carbon-fiber composites are an alternative to glass-fiber composites because they are stiffer and therefore have better potential for structural applications. They can also be made lighter than their glass-reinforced counterparts, providing a significantly higher weight-savings potential. Carbon fiber composites' most significant use to date has been in concept cars, e.g., about two decades ago by Ford Granada and relatively recent the 1991 Ultralite by General Motors. The automaker BMW has recently announced its plan of making lightweight carbon- 
fiber-reinforced car bodies under production conditions by 2005, by using in its recently unveiled Z22 concept vehicle, the full-sized passenger vehicle based on the 528i sport wagon (Miel 2000). The concept vehicles, P2000 and ESX2—developed by Ford and DaimlerChrysler, respectively, to meet the Partnership for a New Generation of Vehicles' (PNGV) goal of producing vehicles three times more fuel efficient than current vehicles-are expected to contain $8 \mathrm{lbs}$ and $24 \mathrm{lbs}$ of carbon fiber, respectively. Primarily because of cost, carbon fiberreinforced polymer composites have not been considered as the leading near-term structural material by the PNGV. 


\section{COST STRUCTURE OF COMPOSITES}

This assessment of the current viability of composites in automotive applications is based on the very limited cost information currently available. The specific cost estimate provided for a given manufacturing technology should not be generalized for that technology. Each cost estimate is based on many underlying assumptions, both technical and economic; the degree of overall cost sensitivity to these assumptions will vary across different technologies. The use of different sources of information also poses a problem in the consistency of input assumptions made for the cost estimation. The information drawn from various sources in the literature and used in this assessment does not allow one-to-one comparison among various manufacturing technologies for a part application; it does, however, allow one to assess general, qualitative trends and to identify major barriers to the economic viability of composite technologies.

Most of the cost studies done to date have examined body-in-white (BIW) designs to demonstrate the economic viability of composites in automotive applications. The monocoque BIW design of composites has been found to be cost effective only because parts consolidation results in only a small number ( 2-20) of relatively large parts. Figure 1 shows a recent study's cost comparison of two composite monocoque BIW designs (i.e., glass fiber-reinforced thermoset and carbon fiber-reinforced thermoplastic) against the conventional steel unibody for an annual production volume of 250,000 parts (Dieffenbach 1996a). From the cost perspective, these two composite cases provide the two extreme points. Other cases, such as glass fiberreinforced thermoplastics and carbon fiber-reinforced thermosets, will lie between them. This study estimated the costs of glass- and carbon fiber-based composite monocoques to be about $62 \%$ and $76 \%$ higher than conventional steel unibody (Figure 1). The study on which the figure is based assumes the cost of carbon fiber to be $\$ 10 / \mathrm{lb}$. Another study has estimated the cost of carbon fiber-reinforced moncoque thermosets to be in the range of $41-73 \%$ higher than the steel unibody, depending on the type of tooling used (Mascarin et al. 1995).

The main factors affecting the economic viability for the composite vehicles today are the cycle times of glass-reinforced thermosets and the material cost of the carbon fiber-reinforced thermoplastics. The cost comparative study of two composite monocoque BIW designs as discussed above indicates that the material cost contributes $60 \%$ of the total cost of carbon fiber- 


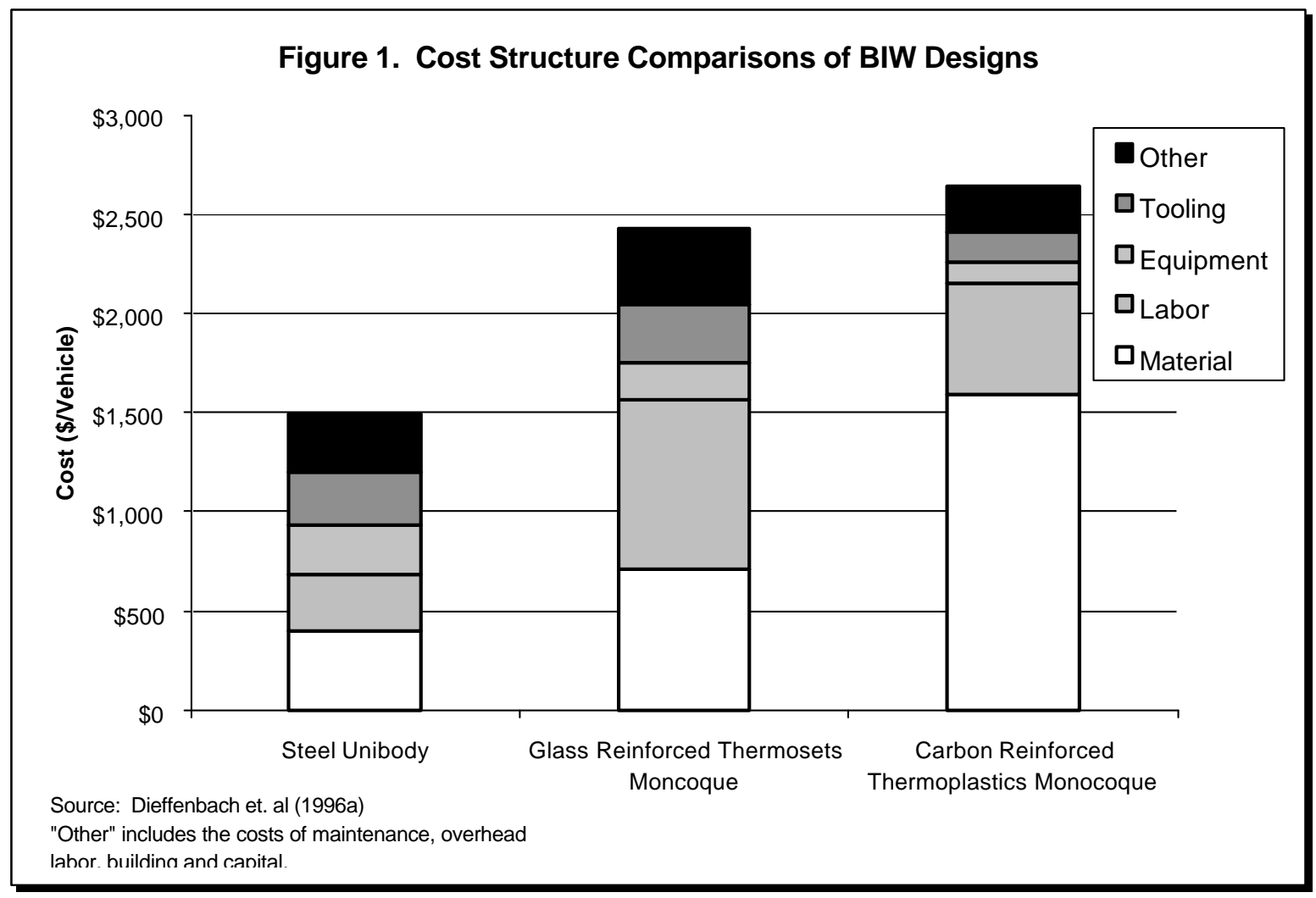

reinforced thermoplastics but only $29 \%$ for glass fiber-reinforced thermosets, as shown in Figure 1. Labor is the second largest contributor to cost, accounting for about $35 \%$ and $21 \%$, respectively, of the cost of carbon fiber-reinforced thermoplastics and glass fiber-reinforced thermosets. The lower labor and tooling cost for the carbon fiber-reinforced thermoplastics design considered in that study results from assumed parts consolidation that makes fenders, roof, and quarter panels integral to the upper body shell and not require additional molding operations as well as higher molding rates offered by thermoplastics. The total number of pieces assumed in this study is 76 for carbon fiber-reinforced thermoplastics versus 81 for glass fiberreinforced thermosets. The glass fiber-reinforced thermoset composites use an entire set of SMC panels. However, lower labor and tooling costs are not large enough to offset carbon fiberreinforced thermoplastics' higher material cost.

Table 1 compares the costs of various BIW designs considered in the study on a $\$ / \mathrm{lb}$ basis (as opposed to the cost comparison in Figure 1, which are based on a given part). These estimates allow one to make a rough cost comparison of the technologies for any part by applying the appropriate weight reduction that the given part can provide. On the basis of unit 
weight alone (not taking into account the weight savings potential that is projected to be $22 \%$ and $48 \%$ for glass fiber-reinforced thermosets and carbon fiber-reinforced thermoplastics, respectively in this study) the cost of a composite monocoque is estimated to be 2-3 times higher than the steel unibody. The difference results primarily from higher material and labor costs. The last column in Table 1 indicates the value of weight savings for the BIW application, expressed as the ratio of the part's cost difference to its weight savings with the steel unibody as the baseline. Because of their higher weight savings potential, carbon-fiber thermoplastic composites look favorable compared to glass-fiber thermoset composites. The value of weight savings of carbon-fiber thermoplastic composites lies within a range of $\$ 1.00-\$ 4.00 / 1 b$, commonly accepted by the automotive industry, where the actual value depends on the application. The value of weight savings is a true measure of the cost effectiveness of a technology, as the range accepted by the industry has been estimated based on life cycle fuel savings resulting from primary and secondary weight savings that lightweight materials provide.

A recent economic analysis examined two representative continuous fiber-reinforced thermoplastic composite parts (i.e., a body panel and a structural wing having weight reduction potential of $42 \%$ and 57\%, respectively) made of polyamide (nylon-12)-reinforced with 50 volume \% glass fiber (Hartmann 1998). The analysis indicates that even with optimizing processing technology that reduces costs by $30-40 \%$, the economic viability of thermoplastic

Table 1. Cost Component Comparisons of Various BIW Designs $(\$ / / b)$

\begin{tabular}{|l|c|c|c|c|c|c|c|}
\hline \multicolumn{1}{|c|}{ BIW Design } & Material & Labor & Eqpt. & Tooling & Other & $\begin{array}{c}\text { Total } \\
\text { Savings* }\end{array}$ \\
\hline Steel Unibody & 0.60 & 0.42 & 0.37 & 0.40 & 0.45 & 2.24 & NA \\
\hline $\begin{array}{l}\text { Glass-reinforced } \\
\text { Thermoset Monocoque }\end{array}$ & 1.38 & 1.64 & 0.36 & 0.57 & 0.74 & 4.68 & 6.21 \\
\hline $\begin{array}{l}\text { Carbon-reinforced } \\
\text { Thermoplastic } \\
\text { Monocoque }\end{array}$ & 4.55 & 1.61 & 0.30 & 0.44 & 0.65 & 7.55 & 3.58 \\
\end{tabular}

* The value here is the ratio of the part's cost difference to its weight savings, with the steel unibody as the baseline Source: Dieffenbach et al. (1996a) 
composites remains a concern. The cost of materials always is a long-term major obstacle to additional improvements, as the materials contribute more than $50 \%$ of total cost even for a production volume greater than 100,000 parts/year.

Another study comparing the cost-effectiveness of thermosets and thermoplastics for underhood powertrain applications concludes that thermoset processes (especially Bulk Molding Composites, which are less expensive than SMC) have a clear cost advantage over thermoplastics depending on part configuration and complexity (Wzorek and Palmer 1998). Since material cost is by far the largest component of manufacturing cost, at least for medium to large part sizes, compression and injection of thermoset resins should always have the cost advantage for underhood powertrain applications (Wzorek and Palmer 1998). Similarly, a cost assessment of front apron automotive part production using two specific liquid composite processes (i.e., RTM and SRIM) indicates that at low and high production volumes, respectively, material cost accounts for $22 \%$ and $38 \%$ of the total manufacturing cost (Ladewig and Wilson 1993).

As composites have lower fixed costs but higher variable costs, they are competitive at a lower production volume in certain automotive applications. For example, at an annual production volume of less than 55,000 units, the composite monocoque was estimated to be competitive with the conventional steel unibody (Mascarin et al. 1995). At low volumes, fixed investment costs dominate the total because there are relatively few parts over which to spread the investment. As a result, low investment parts tend to cost less than high investment parts, often regardless of other factors such as material price and production rate. At higher volumes, material price tends to dominate as the investment cost is spread over a large number of parts. Thus, low material-price parts tend to cost less than high material-price parts, again regardless of other factors. All else being equal, slower production rates tend to reduce the difference between costs for a part at low and high volumes as the effect of investments diminishes. This occurs because of the increased frequency with which new investments must be made to keep up with the target production volume.

Only a few studies have examined the life cycle cost of composites, taking into account the fuel efficiency composites provide during the vehicle operation stage due to light weighting. A 
life cycle cost comparison between a conventional steel unibody and composite monocoque BIW indicates that composite monocoque has a $12 \%$ higher cost than the former (Mascarin and Dieffenbach 1993). The manufacturing cost forms a major share of total life cycle cost, contributing $53 \%$ and $63 \%$ of total for the steel unibody and composite monocoque, respectively, considered in this study. Even at the level of total life cycle cost, the manufacturing cost of composites remains an issue of concern for its competitiveness in the automotive marketplace. It has been estimated that the annual production volume at which the composite monocoque becomes competitive is higher on a life cycle basis, i.e., 75,000, but not a substantial increase from a value of 55,000 when considered from the manufacturing cost perspective (Mascarin et al. 1995). The following paragraphs will delve into further details about the various cost components, i.e., raw material, fabrication using various composite molding processes, and, finally, assembly.

\subsection{RAW MATERIAL}

As discussed above, the major barriers to the use of composite materials in automotive applications today is the raw materials cost, particularly for carbon fiber-reinforced composites. The plastic resin mixtures cost between $\$ 1$ and $\$ 10$ per pound, and glass fibers starts around $\$ 1$ per lb compared to only $\$ 0.40 / 1 b$ for steel. Thermoset materials are generally half the cost of thermoplastics, $\$ 0.75-\$ 0.90 / \mathrm{lb}$ for SMC and BMC compared to $\$ 1.70 / \mathrm{lb}$ for glass-reinforced thermoplastic material. It is estimated that the cost of SMC must approach $\$ 0.50 / \mathrm{lb}$ to be competitive with steel for large-scale body panel applications (Behling 1999). It is this high cost of raw material which makes glass fiber polymeric composites' price competitive with aluminum or steel only in certain applications such as in complex shapes that are prohibitively expensive to form from metal.

The cost of the carbon fibers dominates the raw material cost of composites, for example, it accounts for over $80 \%$ of the total cost at a fiber loading of $41 \%$ by weight for carbon fiberreinforced thermoplastics considered earlier in Figure 1. To be competitive with the conventional steel unibody, it is estimated that the cost of carbon must be $\$ 7.50 / 1 \mathrm{~b}$ if used at $16 \%$ volume (i.e., a volume 50\% less than glass fibers) (Dieffenbach 1996a). If more carbon fibers are needed, i.e., $25 \%$ volume (or $20 \%$ less than glass fibers), then the carbon fiber price 
was calculated to be $\$ 1 / \mathrm{lb}$ for carbon thermoplastics to be competitive. A sensitivity analysis was undertaken to examine the effect of carbon fiber cost only (keeping original $31 \mathrm{vol} \%$ fiber content and other variables unchanged) on the carbon-reinforced thermoplastics monocoque cost (considered in Figure 1) as shown in Figure 2. The figure shows what effect R\&D that reduces carbon fiber cost can have on the economic viability of the carbon-reinforced thermoplastics monocoque. It is estimated here that for the specific body-in white designs considered here, the carbon fiber cost needs to be $\$ 1.56 / 1 b$ for the carbon-reinforced thermoplastics monocoque to be competitive with the steel unibody, and $\$ 8.43 / \mathrm{lb}$ for it to be competitive with the glass-reinforced thermosets monocoque. Achieving the PNGV's target cost of $\$ 3 / 1$ b of carbon fibers in large scale automotive applications - $\$ 5$ less than current costwould significantly reduce the cost differential between the steel unibody and carbon-reinforced thermoplastics monocoque considered in this study from $76 \%$ to $13 \%$. It is projected that a target cost of $\$ 3 / \mathrm{lb}$ would make carbon fibers a viable alternative for many large-scale automotive applications.

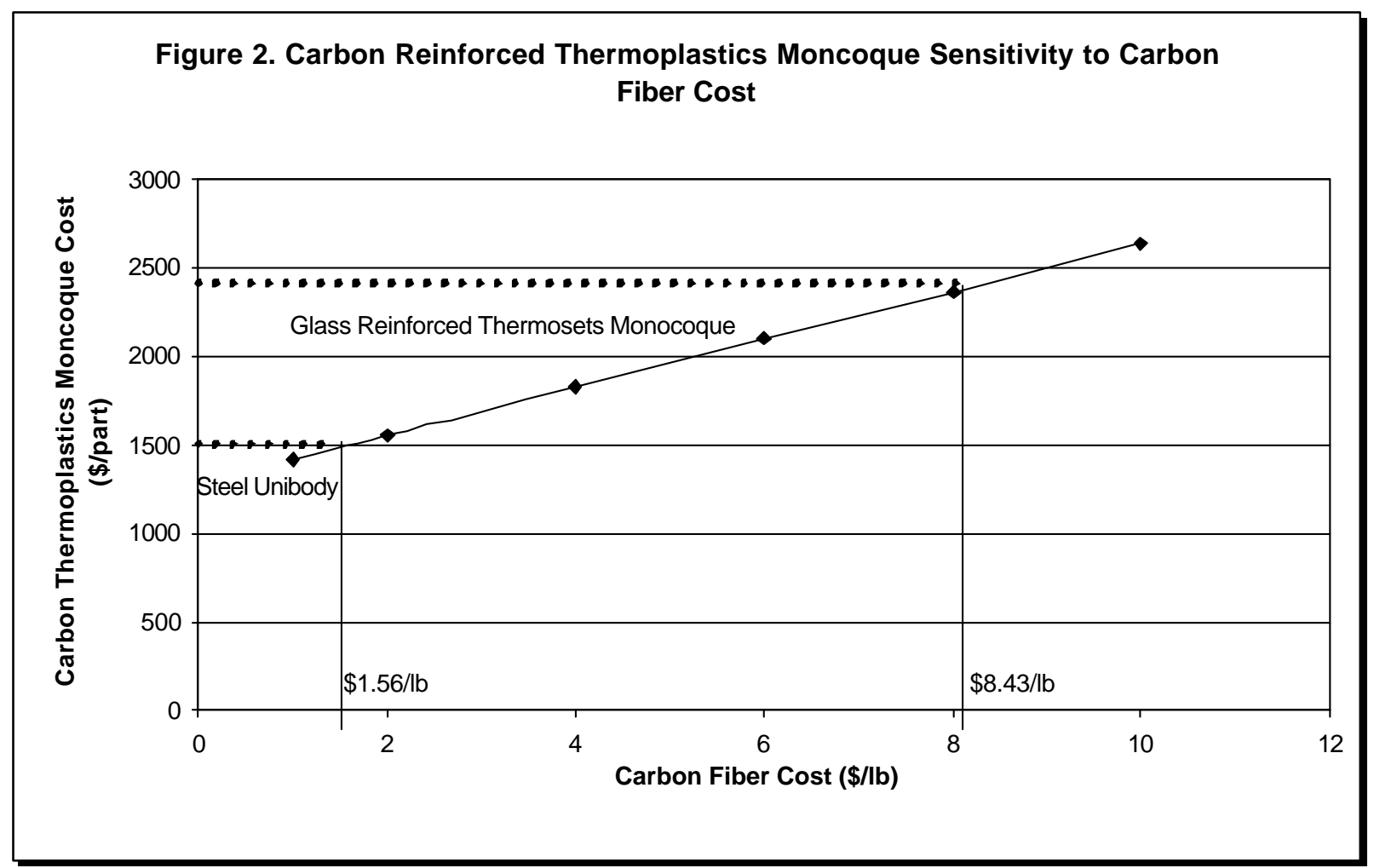


Similarly, a recent study indicates that if the costs of carbon fiber and epoxy prepreg $(65 \%$ fiber and $35 \%$ resin) can be brought below $\$ 5 / \mathrm{lb}$, then there is a huge, real intermediate-term demand.

The demand is estimated to be 750 million to 1 billion lbs of prepreg-or 487.5 to 650 million lbs of carbon fiber-per year within the next decade, compared to a worldwide carbon fiber capacity of less than 85 million lbs today (AMCN 1999). However, it is anticipated that the use of prepregs in automotive applications will not be viable for a large production volume.

Carbon fiber production is slow, capital intensive, and technically challenging. Processing costs are therefore dominated by throughput considerations. As shown in Figure 3, the carbon fiber cost breakdown by major categories indicates raw material (i.e., precursor) costs contribute the most $-44 \%$ of the total. The second largest contributor is capital cost, at $21 \%$ of the total cost. Capital costs are similar to material costs when capital costs include the maintenance, insurance, and taxes on the physical plant. It is the high processing temperature that causes carbon fiber production to be so capital intensive. Economies of scale for carbon fiber production are generally achieved at a production volume of 1,000 tonnes/year but are not enough to lower the cost for large-scale commercial applications (Dieffenbach et al. 1996b). Major changes in processing speed and throughput rates (including at the prepreg stage) are needed to achieve necessary cost reductions. 


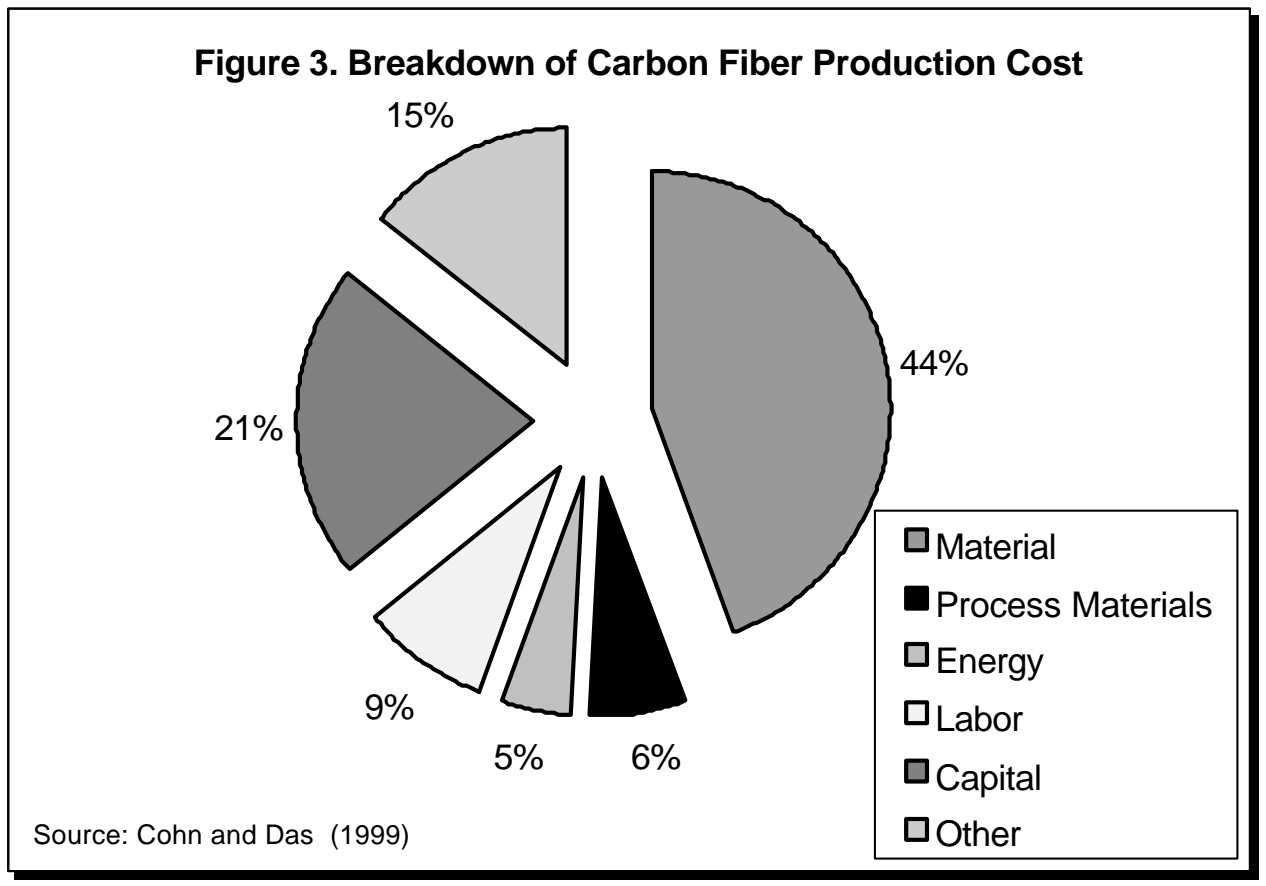

Microwave processing of carbon fibers, which could reduce fiber costs by $20 \%$ mainly by lowering capital cost, is being investigated by ORNL (Cohn et al. 1999). Another area that could offer significant cost reduction potential is the precursor cost, where current R\&D is looking at ways to inexpensively produce precursor materials, e.g., using textile-type acrylic fibers, or fibers produced in-house or by a special single-source or generic multiple sources. It is also essential to develop different grades and combinations of carbon fiber resins for automotive applications that are less costly than current aerospace-grade composites.

\subsection{FABRICATION}

The choice of a specific fabrication method depends on the costs and on the technical requirements of the component to be produced. In order to guarantee economic production, methods with a high throughput are absolutely necessary. High throughput can be achieved by means of low clock times or by means of high integrative parts. Table 2 compares the most commonly used composite fabrication processes available today, addressing their advantages, disadvantages, and cycle time. The use of prepregs, which are reinforced with carbon or glass in fiber and fabric forms coated with epoxy resins, may be suitable for only limited automotive applications because of lower productivity. One of the chief obstacles in the way of achieving 
higher production volumes for structural composites is the time at the preforming stage required to place complex, properly oriented reinforcement in the molding tools. This requirement results in long cycle times, high labor cost, and low productivity of the molding tool investment. A recent study indicates that the cost of preforms contribute about $35 \%$ to the total composite BIW cost, compared to $50 \%$ for molding and 15\% for assembly (Mascarin 2000). Some of the approaches that are used for making preforms are specially knit fabric designed to drape properly for a given component; braided reinforcement over molded foam cores; multiple ply vacuum preforming; and robotically applied chopped fibers known as $\mathrm{P} 4$ process (discussed later).

Table 2. A Comparison of the Most Commonly Used Composite Molding Processes

\begin{tabular}{|c|c|c|c|}
\hline Molding Process & Advantages & Disadvantages & Cycle Time \\
\hline Prepreg & Better resin/fiber control & $\begin{array}{l}\text { Labor intensive for large } \\
\text { complex parts }\end{array}$ & 5-10 hrs. \\
\hline Preforming & $\begin{array}{l}\text { Good moldability with } \\
\text { complicated shapes and } \\
\text { the elimination of } \\
\text { trimming operation }\end{array}$ & $\begin{array}{l}\text { Cost-effective only for } \\
\text { large complicated shape } \\
\text { parts and large scrap } \\
\text { generated when fiber mats } \\
\text { used }\end{array}$ & $\begin{array}{l}\text { 45-75 secs. (Compform } \\
\text { Process) } \\
\text { 4-5 mins (Vacuum } \\
\text { forming) }\end{array}$ \\
\hline RTM & $\begin{array}{l}\text { Inside and outside finish } \\
\text { possible with thickness } \\
\text { control, more complex } \\
\text { parts possible with } \\
\text { vacuum assisted }\end{array}$ & $\begin{array}{l}\text { Low viscosity resin } \\
\text { necessary and the } \\
\text { possibility of voids } \\
\text { formation without vacuum } \\
\text { assisted }\end{array}$ & $\begin{array}{l}\text { 8-10 mins for large parts; } \\
3-4 \text { mins for vacuum } \\
\text { assisted }\end{array}$ \\
\hline $\begin{array}{l}\text { Liquid Compression } \\
\text { Molding }\end{array}$ & $\begin{array}{l}\text { Favored method for mass } \\
\text { production with high fiber } \\
\text { volumes }\end{array}$ & $\begin{array}{l}\text { Expensive set up cost for } \\
\text { low production }\end{array}$ & $1-2$ mins. \\
\hline SMC & $\begin{array}{l}\text { Cost effective for } \\
\text { production volume } 10 \mathrm{~K} \text { - } \\
80 \mathrm{~K} / \text { year. }\end{array}$ & $\begin{array}{l}\text { Minimum weight savings } \\
\text { potential }\end{array}$ & $50-100$ secs \\
\hline RIM & $\begin{array}{l}\text { Low cost tooling where } \\
\text { prototypes can be made } \\
\text { with soft tools }\end{array}$ & $\begin{array}{l}\text { Difficult to control the } \\
\text { process }\end{array}$ & $1-2$ mins \\
\hline BMC & Low cost base material & $\begin{array}{l}\text { Low fiber content, } \\
\text { randomly oriented, low } \\
\text { structural quality, poor } \\
\text { surface finish }\end{array}$ & 30-60 secs. \\
\hline $\begin{array}{l}\text { Extrusion Compression } \\
\text { Molding }\end{array}$ & $\begin{array}{l}\text { Fully automated, variety } \\
\text { of polymers and fibers can } \\
\text { be used with fiber } \\
\text { volumes up to } 60 \% \text { by } \\
\text { weight }\end{array}$ & $\begin{array}{l}\text { Not for surface finish parts } \\
\text { without paint film or } \\
\text { similar process }\end{array}$ & $3-6$ mins \\
\hline $\begin{array}{l}\text { Structural Reaction } \\
\text { Injection Molding }\end{array}$ & $\begin{array}{l}\text { Low tooling cost with the } \\
\text { good surface finish } \\
\text { capability }\end{array}$ & $\begin{array}{l}\text { Difficult to control the } \\
\text { process particularly with } \\
\text { low viscosity resin and } \\
\text { longer cure cycle time. }\end{array}$ & 4 mins \\
\hline
\end{tabular}


The most broadly accepted reinforced thermoset composites used by automakers in today's market include sheet molding composite (SMC), bulk molding composite (BMC), reinforced reaction injection molding (RRIM), and liquid composite molding processes such as structural reaction injection molding (SRIM) and resin transfer molding (RTM). SMC and RRIM are most widely used today, contributing to $48 \%$ and $40 \%$, respectively to the total thermoset components used in the 2000 model year passenger cars (ACA 2000). RTM and SRIM composite molding processes have been considered to provide the best economic balance for the automotive structural products. These processes have favorable cycle times with large parts and produce a surface quality corresponding to the automotive standard. The competitiveness of some of the technologies in terms of annual production volume and part weight is shown in Figure 4. Most fabrication technologies are suited for an annual production volume of less than 50,000. The typical value of molded parts follows closely with the technologies' production volume, i.e., lower $\$ /$ lb parts are produced by high-production volume technologies. The value of products ranges between $\$ 1-\$ 3 / \mathrm{lb}$, with SMC and BMC at the lower end, whereas RTM and SCRIMP (Seemann Composite Resin Infusion Molding Process) processes at the upper end of the range (Busch 2000). Beginning in the fall of 2000, Ford Motor Co. will use SMC for its Explorer cargo box, while General Motors has chosen SRIM and preforms for the Chevrolet 1500 Series Extended Cab Silverado's cargo box. 
Figure 4. Applicability of Various Composite Manufacturing Technologies, by Annual Production Volume and Part Weight

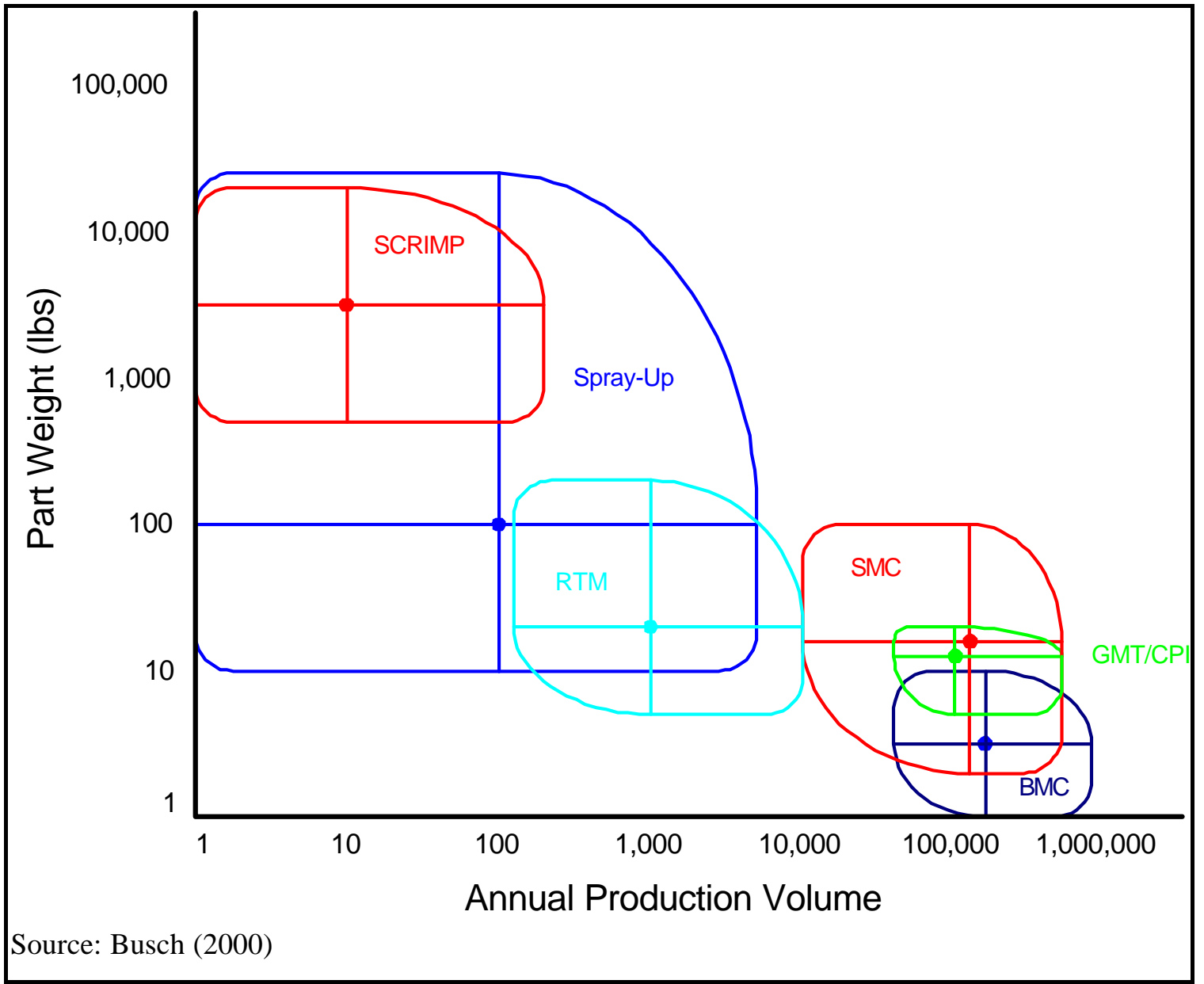

Of the major vertical body panels market shared by composites today, SMC enjoys $71 \%$ share, RIM 7\%, and various thermoplastic materials $22 \%$. One of the reasons for the popularity of SMCs is that they fit well into the existing sheet metal manufacturing and assembly processes and have lower tooling costs, lower capital investment, and reduced capital requirements as compared with steel. Due to lower fiber content, random fiber orientation, and low structural quality, high productivity processes such as SMC and BMC are not suited for the production of dynamically high-loaded space frames. Components with larger surfaces are generally produced in injection processes such as RIM and SRIM. A recent development in RIM technology, with an e-coat capable material, has provided further expansion of RIM materials into body panel applications. The glass-filled thermoplastic components seen mostly today are made by injection/ compression molding. 
It has been reported that composite tooling combined with electron beam curing at high production volume allows a rapid cycle times and lower tooling investment, bringing total manufacturing costs of a composite monocoque to $22 \%$ less than that produced by nickel shell tooling (generally less expensive than steel) (Mascarin et. al 1995). Except for its difficulty in directly producing Class A surfaces and durability, composite tooling could be the best choice for high-volume applications on a manufacturing cost basis alone because soft tooling (i) is cheap to produce, (ii) can be fabricated quickly, and (iii) is compatible with rapid curing technologies, reducing the number of parallel fabrication lines for a given production volume (Mascarin et al. 1995).

For composites to be cost-effective for a wider range of automotive applications, large-scale volume of at least 50,000 units per year-or possibly an order of magnitude higher-is necessary. Although this production scale can be achieved for nonstructural parts, processing technologies for reinforced plastics are better suited to lot sizes of hundreds or thousands rather than hundreds of thousands. The cheapest way to attain cost effectiveness will be to speed up the process, making more parts with the same equipment. However, the manufacturing processes for reinforced polymer-based materials are not amenable to this kind of straightforward scale-up. The polymer processes are inherently slower, taking about a minute or more for plastic parts the size of automobile body panels, compared to less than 10 seconds for stamped steel parts. The cycle time is a function of the complexity and size of the part, as well as resin rheology. The rate of chemical reactions (if too high then difficult to control) or the rate of heat transfer (too rapid cooling results in brittleness) cannot be increased. So, the only alternative is having the multiple machines. However, this would then offset the capital advantage of plastic production and increase administrative overhead.

\subsection{ASSEMBLY}

The contribution of assembly cost to the overall part fabrication cost is estimated to be comparatively low. Comparing the relative contribution of each cost component to the total cost for the BIW designs considered here (earlier in Figure 1) indicates that the cost of assembly using adhesive bonding of composites forms a relatively small share-about $18 \%$ - of the total cost, particularly in the case of polymer composites (Figure 5). In comparison, assembly of the 
steel unibody accounts for about $28 \%$ of the total cost. Due to the relatively smaller cost contribution, the effect of a reduction in assembly time from 30 minutes to 5 minutes, which might come from an alternative bonding approach, has been found to be relatively weak in the BIW designs considered here (Dieffenbach 1996a). However, for the specific BIW designs considered in this study as discussed in Figure 5, this reduction in assembly time would help in getting the cost of composite monocoque BIW within $\$ 500$ of the conventional steel unibody BIW. Although it may seem that the potential of parts consolidation in composites will facilitate lower overall cost, it has been found that the saving in assembly cost is more than offset by drastically increased fabrication cost resulting from the greater up front preform and material setup times (Dieffenbach and Busch 1991). Accordingly, it is important that advanced assembly joining techniques be developed. The use of faster curing methods such as light, microwaves, or electron beams will help to reduce the cost by raising throughput.

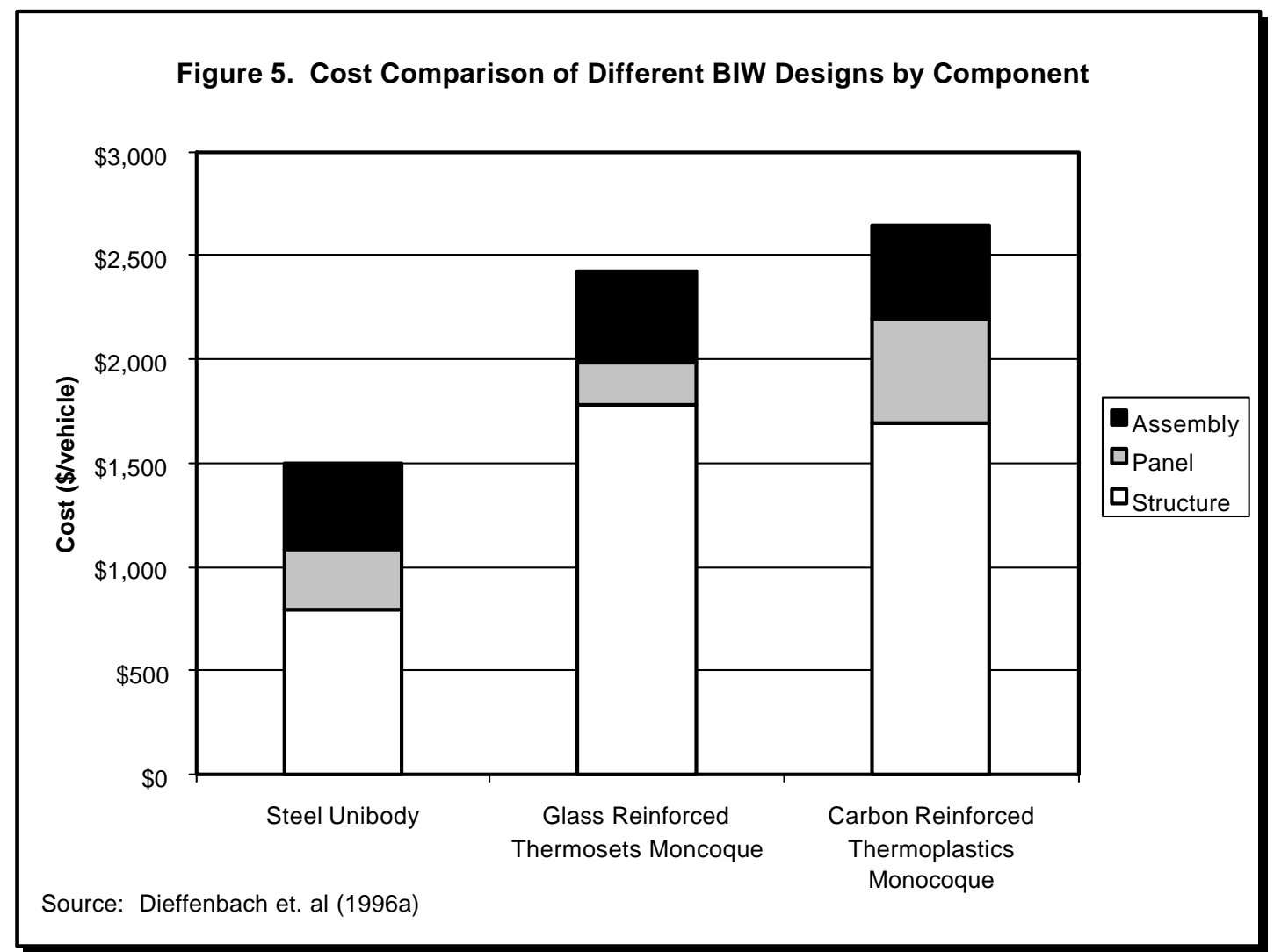




\section{CURRENT DOE RESEARCH ON AUTOMOTIVE COMPOSITES}

DOE research on automotive composites is coordinated through a cooperative arrangement between the U.S. Department of Energy's (DOE) Office of Advanced Automotive Technologies (OAAT) and the U.S. Council for Automotive Research (USCAR). USCAR was formed in 1992 by DaimlerChrysler, Ford, and General Motors to work together on shared technological and environmental concerns. Under the umbrella of USCAR are several technical teams and consortia, each related to a specific aspect of automotive technology. For composites, industry research efforts are coordinated through USCAR's Automotive Composites Consortium (ACC). Composites are a lightweight materials area being supported by the Lightweight Materials Program (LWM) under OAAT. The Program's goal is to develop cost-effective lightweight materials technologies that could reduce vehicle weight without compromising vehicle cost, performance, safety, or recyclability. DOE is attempting to take a comprehensive look at the research needs of the composites industry to make its level of research in a particular area consistent with priorities.

A summary of the DOE research program is provided in the Advanced Automotive Technologies R\&D Plan, where the research portfolio for composites focuses on five major categories of barriers that must be overcome if these materials are to have a more widespread use in automotive applications (DOE 1998). Cost, manufacturability, design data and test methodologies, joining and inspection, and recycling and repair are those major focus areas. Table 3 lists the polymer composite projects currently funded by the DOE Lightweight Materials Program and ACC under those five major categories. Note that some of the projects listed in Table 3 are supported fully by DOE, whereas, some are by both DOE and ACC. The level of ACC support varies by project, anywhere from in-kind support to direct funding. Further details of these projects can be found in the composite materials five year plan (Warren 1999b). To meet DOE's more aggressive weight reduction goal-increasing from a goal of 50\% weight reduction in body and chassis components by 2004 to a value of $60 \%$ by 2011 - the focus of the Program is now shifting from glass-reinforced to carbon-reinforced composite materials. The following paragraphs discuss in detail the major ongoing projects as well as those planned for during the next five years under those five major areas (Warren 1999a, 1999b). The needs that each project 
Table 3. A list of polymer composite projects currently funded by the DOE Lightweight Materials Program and Automotive Composites Consortium

1. Cost

a. Microwave graphitization

b. Advanced processing methods

c. Advanced polymer precursors

d. Coal based precursors

e. Organic/recycled precursors

\section{Manufacturability}

a. P4 preform technologies

b. Thermoplastic composite forming

c. Focal project 2

d. Focal project 3

\section{Design Data and Test Methodologies}

a. Carbon fiber composite durability

b. Deformation and environmentally induced degradation of structural composites

c. Materials screening

d. Computational crashworthiness

e. Crash energy management

f. FP3 design methods

\section{Joining and Inspection}

a. Adhesive bonding of automotive structural composites

b. Adhesive modeling

c. Non-destructive test methodologies

\section{Recycling and Repair}

a. Recycling of polymer matrix composites

is addressing are identified. Mention of non-DOE LWM research is occasional, not exhaustive, and is done only to show the level of interest in a particular technology area. 


\subsection{COST}

Reducing the cost of manufacturing automotive structural components from lighter weight composite materials so that they are competitive with the component (including life cycle) costs of other materials is the major focus here. Although cost reduction is a pervasive factor in all composites R\&D activities, most of the activities in this area are related to materials, the major factor affecting the viability of composites in automotive applications today.

As seen in Figure 1, primary resin and fiber costs present the single greatest barrier to the use of composite materials in automotive applications. Carbon fiber precursors are too expensive, and precursor processing methods are too slow and costly. Most of the ongoing DOE activities related to cost are focused on carbon fiber, where the goal is to lower the cost of high-filamentcount carbon fiber from a current price of $\$ 7$ - 8 per pound to around $\$ 3$ - 5 per pound. This cost reduction goal has gained considerable attention since the DOE focus shifted from glassreinforced composite materials to carbon-reinforced composites. Current research in carbon fiber seeks to use new classes of lower cost precursors and provide the tools for scaling up precursor volumes. Alternate methods for processing precursors into carbon fibers, such as the use of textile-type precursors, also are being pursued. Experimental fibers, referred to as vapor grown, also have been made by chemical vapor deposition. During the next five years, the focus will continue to be on low cost precursor development, early oxidation processing, later oxidation, carbonization and graphitization, and a user's facility for the technology deployment processing line. Development of technologies for continuously monitoring and automatically adjusting processing conditions for the manufacture of carbon fiber is also being planned.

Within five years, DOE will also investigate several other areas to reduce the material cost. A structural thermoplastic system will be developed, having properties equivalent to or better than thermoset systems which are melt recyclable, hot formable, and more repairable at equal or lower cost. In addition, advanced design concepts that take into account significant parts consolidation, lower cost tooling, and the use of multiple materials also will be explored. The use of nanocomposite reinforcing additives in the $20 \%$ to $40 \%$ range to stiffen and strengthen the resin matrix will also be studied. 


\subsection{MANUFACTURABILITY}

Methods for high-volume production of automotive components from lightweight materials have not been adequately developed. Composite processing technologies need to be developed that yield the required component shape and properties in a cost-effective, rapid, repeatable, and environmentally conscious manner. For instance, technologies for high-rate forming and molding of composites for large structural components and high-volume production of continuous fiber preforms are needed.

It is essential that high-rate preforming techniques be developed to obtain chopped-fiber preforms with consistent fiber distribution and density at the volumes required by the automotive industry. DOE has supported the development of a process that is undergoing demonstration testing. The programmable power preform process, known as P4 or the Owens Corning (OC) Preformable System, involves choppers mounted on robots that spray short strands of fiber onto a screen to make a preformed shape. Once the preform is made, it is lifted out and placed in a mold where the preform is injected with a liquid resin that solidifies to make a completed composite part. With the OC process, a large part such as pickup truck box can be made every four minutes. Because glass roving is used for the glass-reinforced composites, material costs are $40 \%$ less than they would be if strand mat were used (Chavka and Dahl 1999). The preform process seeks to demonstrate that large, complex components can be cost-effectively manufactured with reduced cycle times. It is this process that GM has chosen for its Silverado truck cargo boxes.

Adaptation of the P4 process to the carbon fiber application is currently being planned by DOE. For this, it is necessary to develop low-cost, PAN-based carbon fiber rovings that exhibit processing characteristics (both preforming and molding) similar to the currently available glass fiber rovings. This process is already being used with carbon fiber in an evaluation program sponsored by the Air Force for aerospace structures (Reinhart 1999). Compared to conventional composite fabrication methods (e.g., hand lay-up, hat stiffeners), the P4 process may reduce costs as much as $85 \%$ for composite aerospace components. 
Many new technologies are being developed for high-volume production of both thermoplastic and thermoset composite materials. DOE is focusing on the high rate forming processes for shaping carbon fiber-reinforced thermoplastic impregnated composites into automotive shapes. During the next five years, the DOE will focus on the development of rapid curing technologies, molding technologies, and non-liquid molding technologies. Outside of DOE LWM, others also are focusing on processing technologies—one rapid, non-thermal curing method that shows considerable promise is electron beam processing, which is several times faster than standard processing (Cleland 1999). While continuing with the development of an advanced thermoplastic composite forming process, DOE will explore alternate forming technologies, such as non-liquid molding processing technologies including pultrusion and extrusion of continuous and non-continuous carbon fibers. To enhance processability, technologies for altering the surface properties of carbon fiber are also planned for development.

In addition to specific research tasks relating to the manufacturability area, there are validation activities, called focal projects, that demonstrate program goals. Focal projects are centered on specific classes of materials using nonproprietary components and these are done jointly by DOE and ACC. To date, three focal projects have been undertaken; two have been completed. The first focal project, one funded entirely by ACC, was an evaluation of crash energy management in a typical vehicle front-end structure made from glass-reinforced polymer (GRP). In 1996, the front-end section passed a key 35 miles-per-hour crash test. A second focal project demonstrated the ability to produce large, complex composite automotive structures-in this case, pickup truck boxes-from GRP cost-effectively through reduced cycle times. The preforming process used was the P4 process (programmable power preform process) as discussed above. A third focal project now underway reflects the increased emphasis on carbonfiber-based composites. The goal of this focal project is to design and analyze a carbon fiber composite intensive body-in-white that offers a minimum of $60 \%$ weight savings over steel, at or better than cost parity with steel, while meeting manufacturing, assembly, crash, and performance targets. 


\subsection{DESIGN DATA/TEST METHODOLOGIES}

One of the major challenges for the commercialization of polymer composites is the lack of adequate design data (e.g., material property databases), test methods, analytical design tools (i.e., models), and durability data. DOE is focusing on the development of enabling technologies and property data to predict the response of materials in a given structural design after long-term loading, under exposure to different environments, and in crash events.

Research is underway and predictive models are being developed to build understanding of and predictive capability to assess the effects of low-energy impacts, creep, fatigue, automotive fluids, temperature extremes, and the synergistic effects of environmental factors on materials. Technologies are being pursued to develop design methodologies and material use philosophies that take advantage of the positive properties of composite materials while minimizing the effects of their less desirable properties. DOE is also investigating long-term environmental durability, test methodologies, design rules and design methodologies for carbon-fiber-based composite systems that can be used to produce large structural components. Development of equipment and methods for short-term durability testing of composite materials is also under consideration. These methods are being validated by joint DOE/ACC focal projects (as discussed in detail under Sect. 4.2) that develop production prototype test articles that represent automotive structures and subsystems.

Theoretical and computational models are being developed for predicting energy absorption and dissipation in automotive composites. These models are tools designers need to minimize component weight while maximizing occupant safety. Modeling technologies for predicting crash behavior both at the level of material as well as composite structure are in the DOE fiveyear research portfolio. Also during the next five years, DOE will develop advanced design methodologies and test specific crash zones and zone design technologies for incorporating energy absorbing zones and materials into primary automotive structures. Experimental and analytical studies will be conducted to develop and validate methods that predict the crash performance of bonded and mechanically fastened structures. 


\subsection{JOINING AND INSPECTION}

High-volume, high-yielding technologies for joining composites to each other and to metal structures in an automotive assembly environment do not currently exist but are being developed. Current efforts concentrate on adhesive formulation, modeling, and processing. Significant work is being conducted to understand the synergistic effects of environmental stressors on adhesive joint integrity. The next five-year research focus is on the development of non-adhesive joining techniques such as chemical bonding of thermoset composites and the joining of carbon fiber based composites to a variety of materials.

Fast, reliable, and affordable methods to test bond integrity and assembled structures are needed. DOE is currently investigating adhesive joining test methods and design procedures, including long-term load history and environmental durability. Methods for evaluating bond integrity are being developed that are able to qualify and quantify bond strength. These methods need to be robust enough for a manufacturing facility, fast enough for a production line, and reliable enough to ensure passenger safety. Current techniques include laser shearography, thermography, and vibrational excitation. DOE is primarily focusing on the development of nonacoustic, non-destruction evaluation (NDE) techniques for adhesive joints, but later will refocus on non-adhesive joints using carbon fiber-reinforced plastics and aluminum.

\subsection{RECYCLING AND REPAIR}

One of the major drawbacks in the use of composites for automotive applications is that technologies for cost-effective recycling and repair of advanced composite materials do not exist. Cost-effective methods for the separation and recycling of composite materials into high-value applications, as opposed to using them only as filler, need to be developed. Methods are being pursued for separating glass and carbon fiber from thermoset and thermoplastic resin systems. Efforts are also underway to identify alternate uses for post-consumer automotive grade composites. The ongoing DOE project in this area focuses on the determination of the technical and economic feasibility of recycling carbon-fiber-reinforced composites, considering various processes for separation and recovery involving both thermoset and thermoplastic matrix 
substrates. A verification of recovery processes at the pilot scale and establishment of design guidelines for compatible plastic types that can be recycled into new products are also in the five-year plan.

Most of the DOE work in the area of composites repair is related directly to the projects being supported in the joining area, as discussed earlier under Sect. 4.4. Robust methods for rapidly and reliably repairing composite structures are needed. The economic viability of repair will be dictated by the cost-effectiveness of joining vs. replacement of components. 


\section{CONCLUSIONS}

The polymer composites in automotive applications today are glass fiber-reinforced thermoset polymers used mostly in non-structural parts of the vehicle especially for low- and mid-volume cars and trucks. Fiber-reinforced thermoplastics and, especially, carbon fiberreinforced thermosets show great potential, the latter having twice the weight reduction potential of glass fiber-reinforced thermoset polymers. Fiber-reinforced thermoplastics share the advantageous properties of polymer matrix composites and are also recyclable, have indefinite shelf life, and feasible for automated, high volume processing with a potential for rapid and low cost fabrication. The cost is the single most major barrier for the limited application of polymer composites in automobiles today.

Most of the cost studies of polymer composites are for body-in-white (BIW) applications because of the significant weight reduction potential BIWs offer. On a $\$ / \mathrm{lb}$ basis, the cost of polymer composites is about 2-3 times higher than steel, but a recent study comparing the composite monocoque designs indicates that the cost of glass-fiber-reinforced thermosets and carbon-fiber-reinforced thermoplastics are about $62 \%$ and $76 \%$ higher than the conventional steel unibody. However, because of the higher weight reduction potential of, the value of carbonfiber-reinforced composites' weight savings lies in the range of $\$ 1.00-\$ 4.00 / \mathrm{lb}$. Even on a life cycle basis, the cost of polymer composites is considerably higher than steel unibodies. The major cost-contributing life cycle stage is manufacturing, which includes material costs. To be cost competitive on a part-by-part substitution, cycle time and material utilization must be improved. The material cost plays a key role, particularly at the higher production volume and for carbon-fiber-reinforced thermoplastic composites. For the application in structural components where the weight savings potential is less than for the body-in-white, even larger reduction in the material cost would be necessary. The cost of carbon fiber needs to drop by $50 \%$ (i.e., to the $\$ 3-\$ 5 / 1 b$ range) and smaller cost reductions in other thermoplastic materials are needed for the material to be economically viable on a life-cycle basis.

The need for a shorter cycle time for a typical composite molding process is a challenging one. Short cycle times achieved by faster cure times may result in products with a shorter shelf life and lower quality. Shortening cure times may not be a feasible option, and strategies to 
determine the most suitable processing method for a given application are needed. Multiple, parallel production lines could be used to improve the viability of polymer composite manufacturing processes for the high-production-volume applications. Although parallel lines may reduce the capital advantage of polymer composites, a significant reduction in material cost and further integration and combination of parts in the design will improve composites' overall economic viability. Further cost studies are warranted to assess the validity of this approach. Similarly, studies are needed to evaluate the current economic viability and research needs for the use of carbon-reinforced-polymer composites in structural applications. To expand the automotive market for fiber-reinforced thermoplastics necessitates optimizing both the materials and their processing technology to achieve a significant improvement in economic performance.

It is a certainty that cost-effectiveness of mass-produced composite components can only be achieved by using low-cost, high-reliability materials, new high-speed processing techniques, and new structural design approaches that are tailored for fiber-reinforced polymer materials. DOE, in partnership with the USCAR's Automotive Composites Consortium (ACC), is sponsoring research under the Lightweight Materials Program that seeks to overcome the barriers to more widespread use of composites in automotive applications. DOE is attempting to take a comprehensive look at the research needs of the composites industry and has been emphasizing areas such as thermoplastic structural composites and the development of new reinforcement technologies such as nanocomposite technology. Its research portfolio is focused on the five major areas of barriers, i.e., cost, manufacturability, design data and test methodologies, joining and inspection, and recycling and repair. Its shift of emphasis to carbon-fiber-reinforced polymer composites from glass-fiber-reinforced polymer composites is appropriate to achieve its and the industry's aggressive weight reduction goal. Although cost reduction is a pervasive factor in all its composites R\&D activities, it is appropriate to focus the "cost" area on materials, primarily carbon fiber. Since the fiber-reinforced thermoplastics show great potential for automotive applications, more research devoted to reducing their material cost is needed. To improve the manufacturability of polymer composites, development of high-volume production manufacturing processes that reduce cycle times should remain a DOE LWM research priority. Projects like the development of the $\mathrm{P} 4$ high-rate preforming technique that has demonstrated a significant reduction in cycle time should be pursued. It is also important that more emphasis be put on the manufacturability of carbon-fiber-reinforced thermoplastics materials that show a 
great potential for high performance structural automotive applications. The focal projects, centered on specific classes of materials using nonproprietary components, considered as a part of validation activities are demonstrating program goals and reducing the lead time to bring the new technology into the marketplace.

Although the other three areas of DOE research activities, i.e., design data/test methodologies, joining and inspection, and recycling and repair, have a less direct bearing on the cost, they are also important for the overall economic viability of composites. Design methodologies, materials use philosophies, and durability data that will enhance material choice need to be developed. Improving material choice improves the economic viability of the class of materials. Economic viability assessments of composite joining and inspection technology is needed to determine whether reduced assembly costs (from parts consolidation) offsets the higher manufacturing cost (of large parts). The recyclability of thermoplastics shows a great promise, but DOE must continue the development of cost-effective means of recycling, including the separation of fibers from the resin matrix material. It is clear that an aggressive $R \& D$ portfolio should be followed. Several orders of cost reduction resulting from major breakthroughs are needed before composites become the material of choice for the automakers. Until then, composites' application will continue to be seen in low-volume, niche market vehicles. 


\section{REFERENCES}

Advanced Materials \& Composites News (Composites) (1999) "Auto R\&D and the "Right Costs" May Lead to Huge Demand, Well Above Current World Supply for Carbon Fibers and Prepregs," August 16.

Advanced Materials \& Composite News (AMCN) (1999) “Carbon Fiber Situation Cloudy Now, But With a Brighter Future," 21(16, Aug 16).

Aronson, Robert B. (1999), "Materials for the Next Generation Vehicle," Manufacturing Engineering, August.

Automotive Composites Alliance (ACA) (2000) "2000 Model Year Passenger Car and Truck Thermoset Composite Components," Troy, MI.

Behling, H. (1999) "My Car Is Made From Tupperware? A Look at Composite Body Panels," available online at http://rouge.engr.wisc.edu/epd/steuber/behling.html.

Buchholz, K. (1998). “Lightweight Body Panel Materials,” Automotive Engineering International, Vol. 106, No. 12, Dec., pp. 19-22.

Busch, J. (2000). “Composite Technologies: An Overview of Business Potentials," White Working Paper, IBIS Associates, Inc., Wellesley, MA.

Chapman, G. B. (1999). “A Thermoplastic Approach to a Composite Automotive Body,” SAE Paper No. 1999-01-3222, The Society of Automotive Engineers, Warrendale, PA.

Chavka, N. G. and Dahl, J. S. (1999). "P4 Preforming Technology Development Utilizing EGlass and Carbon Fibers," Proceedings of SAMPE-ACE-DOE Advanced Composites Conference, held on Sept. 27-28, in Detroit, MI.

Cleland, Marshall, and Arnold Herer (1999) “New Facilities for High-Power, High-Energy Electron Beam Processing”, $44^{\text {th }}$ International SAMPE Symposium and Exhibition, Evolving and Revolutionary Technologies for the New Millennium, Long Beach, CA, May.

Cohn, S. M. and S. Das (1999). “A Cost Assessment of PAN Carbon Fiber Production Technologies: Conventional and Microwave Cases, draft paper, Oak Ridge National Laboratory, Oak Ridge, TN, Feb. 
Defosse, Matthew T. (1999) "Ford, GM move to composite truck beds", Modern Plastics, October 1 .

Demmler, A. (1998). “Trends in Automotive Materials," Automotive Engineering International, Dec. 1, pp. 26-27.

Dieffenbach, J.R., and J.V. Busch (1991). "The Myths and Realities of Automotive Parts Consolidations: The Case of Composites in Fabrication," paper presented at the 1991 ASM/ESD Advanced Composites Conference.

Dieffenbach, J.R., P.D. Palmer, and A.E. Mascarin (1996a). "Making the PNGV Super Car a Reality with Carbon Fiber: Pragmatic Goal or Pipe Dream?" SAE Paper No. 960243, Society of Automotive Engineers, Warrendale, PA.

Dieffenbach, J.R., P.D. Palmer, and T.M. Backman (1996b). "Carbon Fiber Manufacturing Cost: What Price Doesn't Tell You," paper presented at the International Body and Engineering Conference, held in Detroit, MI, on Oct. 1-3.

Flynn, M. S. and Belzowski, B. M. (1995). "Barriers to Automotive Structural Composites: Concerns, Competition, and Competence, Proceedings of $11^{\text {th }}$ Annual ASM/ESD Advanced Composites Conference and Exposition, Nov., pp. 517-534.

Hartmann, A., A. Woginger, and M. Neitzel (1998). "Cost Effective Processing of Continuous Fiber-reinforced Thermoplastics," Materials Technology 13 (4), pp. 160-165.

James, A. (1999). "ELPO Capable Polyuera RIM: A Breakthrough Material for Composite Body Panel Applications," SAE paper no. 1999-01-3225, Society of Automotive Engineers, Warrendale, PA.

Ladewig, T. S. and T. E. Wilson (1993). "Cost Model Development for the Production of LCM Parts," Proceedings of $9^{\text {th }}$ Annual ASM/ESD Advanced Composites Conference and Exposition, Nov., pp. 699-711.

Martens, Richard (1998) "Selecting Intermediate Performance Resin Systems: What to Look For in Orthophthalic, Isophthalic, and Terephthalic Resins", Composites '98, Composites Fabricators Association, October 21-24.

Mascarin, A.E. and J.R. Dieffenbach. (1993). "Manufacturing and Life Cycle Costs of a Composite Automotive Structure," Society of Plastics Engineers, Antec Conference, May. 
Mascarin, A.E. (2000). Personal communication with Sujit Das, Oak Ridge National Laboratory, IBIS Associates, Wellesley, MA. Mar.

Mascarin, A.E., J.R. Dieffenbach, M.M. Brylawski, D.R. Cramer, and A.B. Lovins (1995).

"Costing the Ultralight in Volume Production: Can Advanced Composite Bodies-In-White Be Affordable?" paper presented at the 1995 International Body Engineering Conference \& Exposition, held on Oct. in Detroit, Michigan.

Miel, Rhoda (2000). "BMW Puts New Design Idea on Carbon-Fiber Diet," Automotive News, vol. 75, no. 5900, pp. 36D, Oct. 23.

Millerschin, E. (1999). “The Rise of Composites in the Automotive Market," Composites Fabrication, pp. 40-42, Jan.

National Research Council (1999). Review of the Research Program of the Partnership for a New Generation of Vehicles: Fifth Report, National Research Council, National Academy Press, Washington, DC.

Reinhart, Theodore (1999) "The Potential of Oriented, Discontinuous Carbon Fiber Preforms for Low Cost High Performance Aerospace Structures", SAMPE-ACEE-DOE Advanced Composites Conference, Planes, Trains, Automobiles, and Bridges Too, Detroit, September.

U.S. Department of Energy (DOE) (1998) Office of Advanced Automotive Technologies R\&D Plan. DOE/ORO/2065, Office of Transportation Technologies, Energy Efficiency and Renewable Energy, Washington, DC, March.

United States Council for Automotive Research (USCAR) (1996), “Costs Must Come Down Dramatically If Composites Are To Compete," www.uscar.org/techno/compcost.htm, Summer/Fall.

Warren, C. D., R. G. Boeman, and F. L. Paulauskas (1994) “Adhesive Bonding of Polymeric Materials for Automotive Applications", Proceedings of the 1994 Annual Automotive Technology Development Contractors Coordination Meeting, October.

Warren, C.D. (1999a). "DOE Automotive Composite Materials Research Efforts," draft paper, Oak Ridge National Laboratory, Oak Ridge, TN.

Warren, C.D. (1999b). "LWM -- Composite Materials: 5 Year Plan,” draft paper, Oak Ridge National Laboratory, Oak Ridge, TN. 
Wzorek, J.F. and Palmer P. D. (1998). "Thermosets versus Thermoplastics for Underhood Powertrain Applications," General Powertrain Congress held in Detroit, MI, June. 


\section{INTERNAL DISTRIBUTION}

1. C. Beasley

2. M. A. Brown

3. T. R. Curlee

4. S. Das

5. W. Craddick

6. S. C. Davis

7. D. L. Greene

8. E. T. Grostick

9. S. G. Hildebrand
10. C. I. Moser

11. T. Schaffhauser

12. R. B. Shelton

13. P. S. Sklad

14. C. D. Warren

15. R. E. Ziegler

16. Central Research Office

17. Laboratory Records (RC)

\section{EXTERNAL DISTRIBUTION}

18. Dr. Lilia A. Abron, President, PEER Consultants, P.C., 1460 Gulf Blvd. Apt.1103, Clearwater, FL 33767.

19. Dr. Douglas Bauer, Executive Director Commission on Engineering and Technical Systems, National Research Council, Harris 280, 2001 Wisconsin Avenue, N.W., Washington, D. C. 20007.

20. Dr. Joseph Carpenter, Office of Transportation Technologies, Energy Efficiency \& Renewable Energy, U.S. Department of Energy, 5G-030, Forrestal Building, 1000 Independence Avenue, S. W., Washington, DC 20585-0121.

21. Dr. Susan L. Cutter, Professor and Chair, Director, Hazards Research Lab, Department of Geography, University of South Carolina, Columbia, SC 29208.

22. Dr. Thomas E. Drabek, Professor, Department of Sociology, University of Denver, Denver, CO 80208-0209.

23. Mr. Michael M. Fisher, Director of Technology, American Plastics Council, 1300 Wilson Boulevard, Suite 800, Arlington, VA 22209.

24. Mr. John Green, The Aluminum Association, 900 19th Street, NW, Washington DC 20006.

25. Mr. P. Richard Rittelmann, FAIA, Executive Vice President, Burt Hill Kosar Rittelmann Associates, 400 Morgan Center, Butler, PA 16001-5977.

26. Dr. Susan F. Tierney, The Economic Resource Group, Inc., One Mifflin Place, Cambridge, MA 02138.

27. Mr. Ed Wall, Office of Transportation Technologies, Energy Efficiency \& Renewable Energy, U.S. Department of Energy, 5G-030/FORS, 1000 Independence Avenue, S.W.,Washington, DC 20585-0121.

28. Dr. C. Michael Walton, Ernest H. Cockrell Centennial Chair in Engineering and Chairman, Department of Civil Engineering, University of Texas at Austin, Austin, TX 78712-1076.

29. OSTI, U. S. Department of Energy, P. O. Box 62, Oak Ridge, TN 37831.

30. ORNL Site Manager, U.S. Department of Energy, Oak Ridge National Laboratory, P. O. Box 2008, Oak Ridge, TN 37831-6269.

31. Transportation Materials Program extra copies to S. A. Moore, 4500N, G-32. 